\title{
Toxoplasma encephalitis in HIV/AIDS patients admitted to the Douala general hospital between 2004 and 2009: a cross sectional study
}

\author{
Henry Namme Luma ${ }^{1,2^{*}}$, Benjamin Clet Nguenkam Tchaleu ${ }^{1,3}$, Yacouba Njankouo Mapoure ${ }^{1,4}$, Elvis Temfack ${ }^{1 *}$,
} Marie Solange Doualla ${ }^{1,2}$, Marie Patrice Halle ${ }^{1,4}$, Henry Achu Joko ${ }^{1}$ and Sinata Koulla-Shiro ${ }^{2}$

\begin{abstract}
Background: It is estimated that about a third of the world's population is chronically infected with Toxoplasma gondii. Toxoplasma encephalitis (TE), which occurs as a reactivation of quiescent chronic infection, is one of the leading causes of central nervous system (CNS) infection in AIDS. Its diagnosis in most centres still remains difficult. We opted to describe the clinical and radiological features of TE as well as in-hospital outcome and its associated factors.

Methods: We carried out a cross sectional study on the clinical case notes of adult patients admitted and treated for TE at the Douala General Hospital, Cameroon between January $1^{\text {st }} 2004$ to December $31^{\text {st }} 2009$.

Results: Of 672 patients admitted during the study period, 14.4\% (97/672) had TE. The mean age was $36.9 \pm 14.1$ years and the median CD4 cell count was $68 / \mathrm{mm}^{3}$ (IQR): 43 - 103). Headache and fever were the most common presenting symptoms in 92.8\% (90/97) and 87.6\% (85/97) of patients. Annular contrast enhanced lesions were the most common brain scan finding in 81.4\% (79/97) of patients. In-hospital mortality was 29.9\% (29/97). Altered sensorium, presence of focal signs, neck stiffness and low CD4 cell count were factors associated with mortality. Adjusting for low CD4 count, altered sensorium remained strongly associated with fatality, adjusted odd ratio (AOR) 3.5 (95\% Cl $1.2-10.5$ ).
\end{abstract}

Conclusion: Toxoplasma encephalitis is common among AIDS patients in Douala. Its high case fatality warrants adequate and compliant prophylactic therapy in severely immune depressed patients as well as early initiation of antiretroviral therapy in HIV-infected patients.

Keywords: Toxoplasma encephalitis, Case fatality, Altered sensorium, HIV-infected

\section{Background}

Globally, about a third of the world's population is chronically infected with Toxoplasma gondii [1]. Toxoplasma encephalitis (TE) is the most frequent cause of focal central nervous system (CNS) infection complicating Acquired Immune Deficiency Syndrome (AIDS) [2]. It has been shown to occur by reactivation of quiescent infection $[3,4]$ as a result of loss of cellular immunity. In the CNS, the predominant neuropathologic feature of TE is multifocal necrotizing encephalitis [5] which progresses to parenchymal abscesses with necrosis and

\footnotetext{
*Correspondence: hnluma@yahoo.com; etemfack@hotmail.com

'Internal Medicine Unit, Douala General Hospital, P.O. Box 4856, Douala, Cameroon

${ }^{2}$ Faculty of Medicine and Biomedical Sciences, University of Yaoundé 1,

Yaoundé, Cameroon

Full list of author information is available at the end of the article
}

surrounding inflammation [6]. This life threatening infection increases in frequency with severity of immune depression $[2,7]$ and has a variable worldwide seroprevalence [8]. In some high income settings with high seroprevalence, it has been estimated that in the absence of prophylaxis 30 to $40 \%$ of patients with AIDS will develop TE [9]. Like most CNS diseases in AIDS, diagnosis of TE is often difficult such that in clinical practice treatment of TE is usually initiated upon presumption based on clinical and radiological features as well as response to treatment $[2,10]$. The advent of highly active antiretroviral therapy (HAART) and its effectiveness in improving the immunological status of AIDS patients has been accompanied by a decrease in incidence of TE in high income settings [11]. In sub Saharan Africa where about two thirds of the global HIV burden is found [12]

\section{Biomed Central}


the picture might be different because many patients still present with severe immune depression and HAART coverage is not yet universal. More so, access to health care is limited, a situation which might underestimate the burden of TE in AIDS. This was the impetus behind this hospital based study whose aim was to define the clinical and radiological features of patients with TE, determine in-hospital outcome and its associated factors.

\section{Methods}

\section{Study setting}

The study was carried out at the Douala General Hospital (DGH), a tertiary referral hospital in Douala, the largest city in Cameroon. It has a capacity of 320 beds and is the most specialised in the sub region. Prior to the study, local institutional ethical clearance of the Douala General Hospital was sought and obtained. At the DGH, HIV diagnosis is made according to guidelines of the Cameroon National AIDS control programme [13] by antibodies detection on two successive samples using a third generation ELISA test BIOREX ${ }^{\circledR}$ (Biorex Diagnostics Limited, Antrim, United Kingdom). If both are positive, a third sample is collected and tested using Genie $^{\circledR}$ III HIV-1/HIV-2 Assay (Bio-Rad Diagnostics, France) to specify whether HIV 1 or HIV 2. These three tests if positive, the patient is declared positive for HIV. In case of any discordance, testing is done with Western blot (New LAV blot, Diagnostics, Pasteur). In this institution, diagnosis of CNS disease follows an algorithm that uses clinical, biological and radiological features as well as patient response to treatment. When a patient presents with clinical signs and/or symptoms relevant to CNS disease, firstly a computerised tomographic (CT) brain scan is done in search of space occupying lesions and/or signs of raised intracranial pressure (IP). In the absence of space occupying lesions, raised IP or any contraindication, a lumbar tap is then done for cerebrospinal fluid analysis.

\section{Study population and diagnosis of TE}

We carried out a cross sectional analysis of the files of all adult ( $>18$ years) HIV- 1 patients admitted in the internal medicine unit of the DGH and treated for TE during the period spanning January $1^{\text {st }} 2004$ and December $31^{\text {st }}$ 2009. The diagnosis of TE was presumed when a patient presented with symptoms (headache, seizures, fever, and altered sensorium) and/or signs (neck stiffness, focal signs) together with single or multiple ring enhanced lesions on CT scan imaging. The diagnosis was only confirmed when a patient improved on antitoxoplasma treatment which is mainly cotrimoxazole in our centre. From the files of these patients, we collected socio-demographic, clinical, radiological information relevant to our study on a case reporting form (CRF).

\section{Data analysis}

The data from the CRF was entered into Epidata 3.1 and exported to STATA 11.2 (Stata Corporation, College Station, Texas) for analysis. Clinical and radiological features were categorised as either present or absent, expressed as a percentage of the study population and reported with their 95\% confidence interval (95\% CI). The main outcome of interest was in-hospital death which was expressed as a percentage of the study population to obtain case fatality rates, it was then categorised as present or absent and through Mantel Haenszel method measure of association with covariates was done. Odd ratios (OR) with their 95\% CI were presented. A threshold of association was defined for a two sided $\mathrm{p}$ value of less than 0.05 .

\section{Results}

\section{Characteristics of study population}

During the study period, 672 HIV infected patients were admitted to the Internal Medicine unit of who 97 fulfilled eligibility for the study, giving a prevalence of toxoplasma encephalitis of $14.4 \%$ (97/672). Of the 97, 52.6\% (51/97) were females (Table 1). The mean age of the study population was $36.9 \pm 14.1$ years and median CD4 cell count was $68 / \mathrm{mm}^{3}$ [Interquartile range (IQR): 43 - 103)], with $73.2 \%$ (71/97) having less than 100 cells $/ \mathrm{mm}^{3}$. Men had lower mean CD4 cell counts than women $(\mathrm{p}<0.001)$.

\section{Clinical and radiological features of patients with TE}

Fever and headache were the most common symptoms (Table 2). Neck stiffness was found in $15.5 \%$ of patients

Table 1 General characteristics of 97 HIV infected patients with presumed toxoplasma encephalitis

\begin{tabular}{ll}
\hline Age groups & $\mathbf{N}(\%)$ \\
\hline$<30$ & $37(38.1)$ \\
$30-39$ & $26(26.8)$ \\
$40-49$ & $17(17.5)$ \\
$50-59$ & $11(11.3)$ \\
$>60$ & $6(6.2)$ \\
Sex & \\
Male & $46(47.4)$ \\
Female & $51(52.6)$ \\
Marital status & \\
Single & $27(27.8)$ \\
Married & $69(71.1)$ \\
Divorced & $1(1.0)$ \\
CD4 cell count per $\mathrm{mm}^{3}$ & \\
$<50$ & $29(29.9)$ \\
$50-99$ & $42(43.3)$ \\
$>100$ & $26(26.8)$ \\
\hline
\end{tabular}


Table 2 Clinical presentation, head CT scan findings and median CD4 counts of 97 HIV positive patients with presumed toxoplasma encephalitis

\begin{tabular}{lcccc}
\hline & N & Prevalence & $\begin{array}{c}\text { 95\% Confidence } \\
\text { Interval (CI) }\end{array}$ & $\begin{array}{c}\text { Median CD4 } \\
\text { count (IQR) }\end{array}$ \\
\hline $\begin{array}{l}\text { Symptoms } \\
\text { Headache }\end{array}$ & 90 & 92.8 & $87.5-98.0$ & $67(41-92)$ \\
Fever & 85 & 87.6 & $80.9-94.3$ & $61(41-90)$ \\
Seizure & 56 & 57.7 & $47.7-67.7$ & $47(28-71)$ \\
$\begin{array}{l}\text { Altered sensorium } \\
\text { Clinical signs }\end{array}$ & 23 & 23.7 & $15.1-32.3$ & $29(17-41)$ \\
$\begin{array}{l}\text { Focal signs } \\
\text { Neck stiffness }\end{array}$ & 64 & 65.9 & $56.4-75.6$ & $53(32-73)$ \\
$\begin{array}{l}\text { CT Scan findings } \\
\text { Annular }\end{array}$ & 79 & 15.5 & $8.1-22.8$ & $33(27-43)$ \\
enhancement & & & & \\
$\begin{array}{l}\text { Nodular } \\
\text { enhancement }\end{array}$ & 3 & 3.1 & $0.4-6.6$ & $33(12-45)$ \\
$\begin{array}{l}\text { Pre-suppurative } \\
\text { encephalitis }\end{array}$ & 15 & 15.5 & $8.1-24.0$ & $60(41-89)$ \\
\hline
\end{tabular}

and these patients had the lowest median CD4 cell count (Table 2). On CT scan, patients who presented with nodular enhanced lesions also had the lowest median CD4 cell count (Table 2).

In-hospital outcome of patients with TE and its associated factors

A total of 29 patients died giving a case fatality rate of 29.9\% (Table 3). Their median CD4 cell count was $41 / \mathrm{mm}^{3}$ (IQR: $24-75)$. Men were more likely to die than women though this was not statistically significant (Table 3). The presence of altered sensorium, focal signs, neck stiffness and low CD4 cell count were all predictors of mortality (Table 3). After adjusting for low CD4 count, altered sensorium remained strongly associated with fatality, adjusted odd ratio (AOR) 3.5 (95\% CI $1.2-10.5, \mathrm{p}=0.02)$.

\section{Discussion}

Our study showed that the prevalence of TE among HIV infected patients was $14.4 \%$, a finding similar to that of another study [14]. It has been shown that in situations of severe immune deficiency the prevalence of TE reflects that of latent toxoplasma infection [15]. Seroprevalence of anti-toxoplasma antibodies which is a proxy of the burden of latent infection could predict the burden of TE especially in areas with high HIV prevalence. In one recent study in Cameroon, the seroprevalence of toxoplasma antibodies in HIV/AIDS patients was a high $69.9 \%$ [16]. In this setting where HAART coverage is low [17] and HIV patients still present with severe immune deficiency, TE might be a major cause of morbidity and mortality whose real picture is still unclear. This
Table 3 Case fatality rate of presumed toxoplasma encephalitis and associated factors

\begin{tabular}{|c|c|c|c|c|c|}
\hline & $\mathrm{N}$ & $\begin{array}{l}\text { Number } \\
\text { of death }\end{array}$ & $\begin{array}{l}\text { \% Death of study } \\
\text { population }\end{array}$ & $\begin{array}{c}\text { OR } \\
(95 \% \mathrm{Cl})\end{array}$ & $P$ value \\
\hline \multicolumn{6}{|l|}{ Age } \\
\hline$<40$ & 63 & 22 & 22.7 & 1 & 0.1 \\
\hline$>40$ & 34 & 7 & 7.2 & $0.5(0.2-1.3)$ & \\
\hline \multicolumn{6}{|l|}{ Sex } \\
\hline Female & 51 & 11 & 11.8 & 1 & 0.06 \\
\hline Male & 46 & 18 & 18.6 & $2.3(0.9-5.8)$ & \\
\hline \multicolumn{6}{|c|}{ Altered sensorium } \\
\hline No & 74 & 16 & 16.5 & 1 & 0.002 \\
\hline Yes & 23 & 13 & 13.4 & $4.7(1.6-13.5)$ & \\
\hline \multicolumn{6}{|l|}{ Focal signs } \\
\hline No & 33 & 4 & 4.1 & 1 & 0.006 \\
\hline Yes & 64 & 25 & 25.8 & $4.6(1.4-15.6)$ & \\
\hline \multicolumn{6}{|l|}{ Seizures } \\
\hline No & 41 & 7 & 7.2 & 1 & 0.02 \\
\hline Yes & 56 & 22 & 22.7 & $3.1(1.1-8.6)$ & \\
\hline \multicolumn{6}{|c|}{ Neck stiffness } \\
\hline No & 82 & 21 & 21.6 & 1 & 0.03 \\
\hline Yes & 15 & 8 & 8.2 & $3.3(1.1-10.2)$ & \\
\hline \multicolumn{6}{|c|}{ CD4 cell count } \\
\hline$>100 / \mathrm{mm}^{3}$ & 26 & 3 & 3.1 & 1 & 0.001 \\
\hline$<100 / \mathrm{mm}^{3}$ & 71 & 26 & 26.8 & $4.4(1.5-16.9)$ & \\
\hline Total & 97 & 29 & 29.9 & 1 & I \\
\hline
\end{tabular}

therefore calls for systematic primary anti-toxoplasma prophylaxis for patients with low CD4 counts.

Clinically, patients with TE usually have a sub-acute presentation over several weeks with symptoms and signs usually limited to the CNS including headaches, fever, psychomotor or behavioural abnormalities, confusion, focal signs and seizures [18]. In our study, headaches and fever were the most common symptoms. Other studies similarly found headaches and fever present in over $50 \%$ of patients $[14,19]$. The prevalence of seizures in our study was similar to that of a Malian study [20] but higher than that in another town in Cameroon [21]. This difference might be because of the referral nature of our institution whereby seizures being a dramatic clinical presentation, patients are more easily referred. The occurrence of focal signs in our study was concordant with that of other studies [20-22]. In view of the above findings, CNS symptoms and signs in an HIV infected patient should be promptly investigated and early empirical treatment for possible TE commenced [23].

Brain CT scan examination has been shown to be the most useful means by which the diagnosis of TE could be presumed [14]. All our patients had a brain scan; this is not always the case in most hospitals in Cameroon due to lack of CT scan machines. In such cases, empirical treatment is advised even though it might lead to 
multiple drug administration targeting numerous differential diagnoses especially as the clinical picture of $\mathrm{TE}$ varies and is not specific. This approach however could help reduce TE -associated mortality. On the other hand, CT scan findings are not pathognomonic: differential diagnoses include tuberculoma and primary CNS lymphoma depending on the setting [23]. The typically described ring enhancing lesion was found in $81.4 \%$ of our patients, similar to another study [22].

TE is more common in the advanced stage of HIV disease when CD4 count is low [2,7]. The risk of opportunistic infections increases markedly when values fall below $200 / \mathrm{mm}^{3}$ [15]. Many studies have reported a significant relationship between CD4 cell counts of less than 100 cells $/ \mathrm{mm}^{3}$ and the development of TE [2,7]: $73.2 \%$ of our patients had CD4 counts of less $100 / \mathrm{mm}^{3}$.

The case fatality was $29.9 \%$ in our study. Though similar to that in other studies $[14,22]$ such high case fatality was surprising because the disease can be prevented by adequate prophylactic therapy and more so treatment is readily available [24]. In our setting, this high case fatality could be explained by the fact that on the one hand, most physicians neglect primary prevention of $\mathrm{TE}$ and on the other, patients on prophylaxis may not be compliant with their treatment. Furthermore, empirical treatment even when indicated is usually commenced late because many patients seek medical care only when their clinical state markedly deteriorates. This therefore warrants continued awareness by health care providers on primary prevention and early treatments as this could considerably reduce mortality. Low CD4 count was a predictor of mortality and irrespective of CD4 count, altered sensorium, an index of severe CNS disease was independently associated with mortality. This is a reflection of the health system of our setting where patients only seek care when their disease is at the terminal stage. Patients' sensitisation on the importance of early medical care as well as the reorganisation of the health system to ease access to care, are important steps to reduce TE-associated mortality.

There were some limitations in our study. The diagnosis of TE which remains presumptive may have led to under estimation or over estimation of the burden of TE. Response to treatment which was used as an index to confirm diagnosis of TE was useful only for patients with good response suggesting that some deaths might have been due to a cause other than TE. Moreover, information on anti-toxoplasma prophylaxis and HAART were not included in our analysis because they were consistently not available in patient records.

\section{Conclusion}

TE is a common cause of morbidity and mortality among severely immune depressed HIV-infected patients in Cameroon. Though relatively easy to treat, a definitive diagnosis of TE is still difficult in most centres in Cameroon. The case fatality rate of TE is high; hence primary prophylaxis with adequate compliance should be instituted among patients with severe immune depression as well as early initiation of antiretroviral therapy in HIVinfected patients to avoid severe immune depression.

\section{Competing interest}

The authors declare no conflict of interest.

\section{Authors' contributions}

HNL, BCNT, YNM, ET and SKS designed the study. BCNT, YNM and HAJ collected the data. HNL and ET analysed the data and did manuscript write up, assisted by MPH and MSD. SKS, MSD and HNL proofread the manuscript. All authors agreed with the final manuscript to be submitted.

\section{Acknowledgments}

The authors are grateful to the personnel of the internal Medicine unit of the Douala General Hospital. Special thanks also go to the member s of the Douala Research Network (DRN) for their invaluable contribution to this piece of work.

\section{Author details}

'Internal Medicine Unit, Douala General Hospital, P.O. Box 4856, Douala, Cameroon. ${ }^{2}$ Faculty of Medicine and Biomedical Sciences, University of Yaoundé 1 , Yaoundé, Cameroon. ${ }^{3}$ Université des Montagnes, Bagangté, Cameroon. ${ }^{4}$ Faculty of Medicine and Pharmaceutical Sciences, University of Douala, Douala, Cameroon.

Received: 12 December 2012 Accepted: 20 March 2013

Published: 12 April 2013

\section{References}

1. Prandota J: The importance of toxoplasma gondii infection in diseases presenting with headaches. Headaches and aseptic meningitis may be manifestations of the jarisch-herxheimer reaction. Int J Neurosci 2009, 119(12):2144-2182.

2. Luft BJ, Remington JS: Clinical infectious diseases: an official publication of the infectious diseases society of America. Toxoplasmic encephalitis in AIDS 1992, 15(2):211-222

3. Saadatnia G, Golkar M: A review on human toxoplasmosis. Scand I Infect Dis 2012, 44(11):805-814.

4. Goncharov DB, Gubareva EV, Kobets NV, Domonova EA, levleva ES: Toxoplasmosis in HIV infection: invasion reactivation criteria. Zh Mikrobiol Epidemiol Immunobiol 2012, 4(88):92-p. 92.

5. Mamidi A, DeSimone JA, Pomerantz RJ: Central nervous system infections in individuals with HIV-1 infection. J Neurovirol 2002, 8(3):158-167.

6. Skiest DJ, Erdman W, Chang WE, Oz OK, Ware A, Fleckenstein J: SPECT thallium-201 combined with toxoplasma serology for the presumptive diagnosis of focal central nervous system mass lesions in patients with AIDS. J Infect 2000, 40(3):274-281.

7. Nascimento LV, Stollar F, Tavares LB, Cavasini CE, Maia IL, Cordeiro JA, et al: Risk factors for toxoplasmic encephalitis in HIV-infected patients: a case-control study in brazil. Ann Trop Med Parasitol 2001, 95(6):587-593.

8. Chiang TY, Hsieh HH, Kuo MC, Chiu KT, Lin WC, Fan CK, et al: Seroepidemiology of toxoplasma gondii infection among healthy blood donors in Taiwan. PLoS One 2012, 7(10):e48139.

9. Leport C, Ambroise-Thomas P, Bazin C, Chene G, Derouin F, Katlama C, et al: Risk factors of the occurrence of cerebral toxoplasmosis in patients with HIV infection. Definition of indications of primary prevention. Proposals of the toxoplasmosis and other protozoan infections group. Coordinated action N.5 - 1996 February. Presse Med 1996, 25(11):519-520.

10. Cohen BA: Neurologic manifestations of toxoplasmosis in AIDS. Semin Neurol 1999, 19(2):201-211.

11. Abgrall S, Rabaud C, Costagliola D: Incidence and risk factors for toxoplasmic encephalitis in human immunodeficiency virus-infected patients before and during the highly active antiretroviral therapy era. Clinical infectious diseases: an official publication of the Infectious Diseases Society of America 2001, 33(10):1747-1755. 
12. UNAIDS: Report on the global HIV/AIDS epidemic. Geneva: Joint United Nations Programme on HIV/AIDS; 2011.

13. Central Technical Group of the National AIDS control Committee (Ed): Cameroon national HIVIAIDS control strategic plan. Yaounde, Cameroon: Ministry of Public Health; 2006-2010.

14. Nissapatorn V, Lee C, Quek KF, Leong CL, Mahmud R, Abdullah KA: Toxoplasmosis in HIV/AIDS patients: a current situation. Jpn J Infect Dis 2004, 57(4):160-165.

15. Belanger F, Derouin F, Grangeot-Keros L, Meyer L: Incidence and risk factors of toxoplasmosis in a cohort of human immunodeficiency virusinfected patients: 1988-1995. HEMOCO and SEROCO study groups. Clinical infectious diseases: an official publication of the Infectious Diseases Society of America 1999, 28(3):575-581.

16. Assob JC, Njunda AL, Nsagha DS, Kamga HL, Weledji PE, Che VB: Toxoplasma antibodies amongst HIV/AIDS patients attending the University Teaching Hospital Yaounde, in Cameroon. Afr J Clin Exp Microbiol 2011, 12(3):1119-1123.

17. Loubiere S, Boyer S, Protopopescu C, Bonono CR, Abega SC, Spire B, et al: Decentralization of HIV care in cameroon: increased access to antiretroviral treatment and associated persistent barriers. Health Policy 2009, 92(2-3):165-173.

18. Skiest DJ: Focal neurological disease in patients with acquired immunodeficiency syndrome. Clinical infectious diseases: an official publication of the Infectious Diseases Society of America 2002, 34(1):103-115.

19. Raffi F, Aboulker JP, Michelet C, Reliquet V, Pelloux H, Huart A, et al: A prospective study of criteria for the diagnosis of toxoplasmic encephalitis in 186 AIDS patients. The BIOTOXO study group. AIDS 1997 11(2):177-184

20. Goita D, Karambe M, Dembele JP, Sogoba D, Sidibe AF, Diaby S, et al: Cerebral toxoplasmosis during AIDS in the infectious diseases department of point-G teaching hospital, Bamako, Mali. Le Mali medical 2012, 27(1):p. 47-p. 50.

21. Magnerou AM, Sini V, Ongolo-zogo P, Fonsah JY, Njamnshi AK, Kaptue L: Clinical, brain imaging and therapeutic evaluation of toxoplasma encephalitis in HIV-infected patients in yaounde. Retrovirology 2012, 9(1):145.

22. Antinori A, Larussa D, Cingolani A, Lorenzini P, Bossolasco S, Finazzi MG, et al: Prevalence, associated factors, and prognostic determinants of AIDSrelated toxoplasmic encephalitis in the era of advanced highly active antiretroviral therapy. Clinical infectious diseases: an official publication of the Infectious Diseases Society of America 2004, 39(11):1681-1691.

23. Dedicoat M, Livesley N: Management of toxoplasmic encephalitis in HIVinfected adults (with an emphasis on resource-poor settings). Cochrane Database Syst Rev 2006, 3, CD005420.

24. Antinori A, Murri R, Ammassari A, De Luca A, Linzalone A, Cingolani A, et al: Aerosolized pentamidine, cotrimoxazole and dapsone-pyrimethamine for primary prophylaxis of pneumocystis carinii pneumonia and toxoplasmic encephalitis. AIDS 1995, 9(12):1343-1350.

doi:10.1186/1756-0500-6-146

Cite this article as: Luma et al:: Toxoplasma encephalitis in HIV/AIDS patients admitted to the Douala general hospital between 2004 and 2009: a cross sectional study. BMC Research Notes 2013 6:146.

\section{Submit your next manuscript to BioMed Central and take full advantage of:}

- Convenient online submission

- Thorough peer review

- No space constraints or color figure charges

- Immediate publication on acceptance

- Inclusion in PubMed, CAS, Scopus and Google Scholar

- Research which is freely available for redistribution 